\title{
Antibody Prevalence to Influenza Type A in Wild Boars of Northern Ukraine
}

\author{
Ganna Kovalenko*, Ihor Halka and Aliona Molozhanova \\ Research Training Center for Animal Disease Diagnostics, Institute of Veterinary Medicine of the National Academy of Agrarian \\ Sciences., Kyiv, Ukraine
}

\section{Objective}

A preliminary serological survey was carried out to assess the likelihood of Influenza A (IA) infection in wild boars and begin to characterize the role of wild boars in the epidemiology of the IA virus.

\section{Introduction}

Domestic swine have been viewed as important for the adaptation and spillover of IA from birds into human populations as they are sensitive to both avian and mammalian (including human) influenza viruses [1]. However, in much of Eurasia and North America wild swine are geographically widespread, abundant and often come in close contact with humans in rural and agricultural settings. Until recently, little attention has been paid to this as an alternate route for IA transmission to human and domestic populations and its significance is not clear.

Therefore, the monitoring of the exposure of wild mammals to IA was viewed as essential as potential vectors impacting domestic animals and public health.

\section{Methods}

From September to December 2014, wild boar sera were collected by professional hunters in 4 Oblasts of Ukraine: Volyn, Rivne, Zhytomyr, and Chernihiv. Blood was collected from jugular veins. Sera were collected in Eppendorf type tubes, separated from whole blood without centrifugation and stored at -20C until serologically tested. To detect antibodies to IA, a blocking ELISA was used. Serum samples were tested using commercial test kits "Influenza A Ab Test" (IDEXX, USA). Specific antibodies in wild boar serum samples were detected based on manufacturer's instructions. Briefly, sera were diluted 1:10, and incubated in test wells for 60 minutes at room temperature, followed by three washes. Anti-IA Horseradish Peroxidase HRP conjugate was then added and incubated for 30 minutes at room temperature. Following three washes, 3',5,5'-tetramethylbenzidine (TMB), as a substrate, was added and incubated for 15 minutes. Absorbencies were measured at 650 A using a iMark Microplate Absorbance Reader and data were analyzed using Microsoft Excel. Based on the manufacturer's instructions, a serum sample was considered positive if the sample/ negative control ratio $(\mathrm{S} / \mathrm{N})$ did not exceed a threshold of 0.60 . Statistical analyses were performed with the program "Statistics Calculator".

\section{Results}

Sera from 120 wild boars that were shot in 2014 were tested. Thirty boars from each of 4 Oblasts were collected in the north central and northwestern regions of Ukraine. Antibodies against IAV were detected using ELISA in 27 samples (22.5\%), (Table 1). Antibodies to IA virus were detected in at least some of the wild boars from all of the 4 Oblasts. The highest percentages of seropositive samples were detected in wild boar from Volyn and Zhytomyr Oblasts (Fig. 1). The prevalence differences were statistically significant only between samples from Volyn and Chernihiv Oblasts $(\mathrm{P}<0.05)$. The average $\mathrm{S} / \mathrm{N}$ value of all positive serum samples was $0.36 \pm 0.03$.

\section{Conclusions}

This preliminary survey of IA antibodies in wild boar populations of northern Ukraine indicates a substantial presence of exposure to IAV throughout the region.

Infection of wild boar populations provides an alternative or additional route for spillover from wild populations to domestic animals and humans. This potential has received relatively little attention until recently, likely in part because feral swine populations have not been viewed as a serious challenge in most regions of the world where the natural history of IA has received serious study.

Table 1 Seroprevalence of IA virus in wild boars in Ukraine

Figure 1 Serological surveillance of wild boars for IA virus in northern Ukraine

Table 1

\begin{tabular}{|c|c|c|c|c|c|}
\hline Region & Investigated samples & \multicolumn{2}{|c|}{ Positive samples } & \multicolumn{2}{c|}{ Negative samples } \\
\hline Volyn & 30 & 11 & $36.6 \%$ & 19 & $63.3 \%$ \\
\hline Rivne & 30 & 5 & $16.6 \%$ & 25 & $83.3 \%$ \\
\hline Zhytomyr & 30 & 7 & $23.3 \%$ & 23 & $76.6 \%$ \\
\hline Chernihiv & 30 & 4 & $13.3 \%$ & 26 & $86.6 \%$ \\
\hline In total & 30 & 27 & $22.5 \%$ & 93 & $77.5 \%$ \\
\hline
\end{tabular}

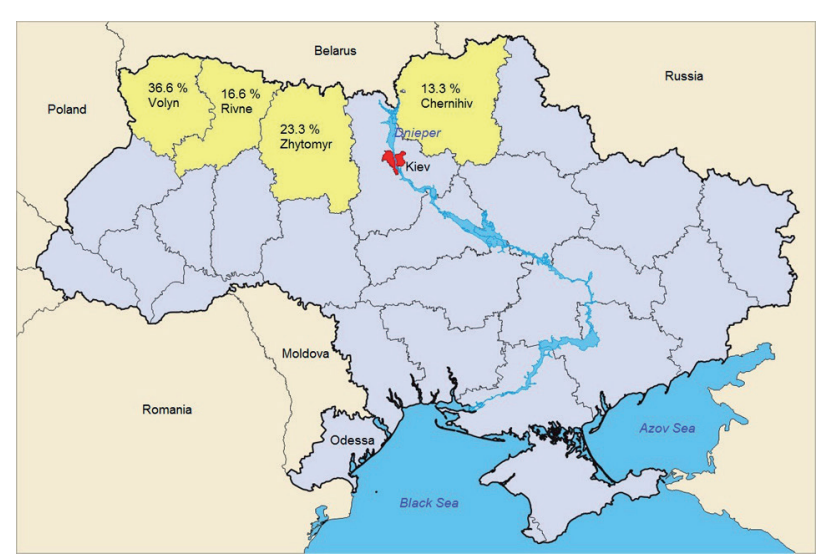

\section{Keywords}

Influenza A virus; seroprevalence; wild boars; Ukraine

\section{Acknowledgments}

Thanks to all employees of the laboratory of the Research Training Center for Animal Disease Diagnostics (IVM, NAAS) for conscientious cooperation.

\section{References}

1. Runstadler J. et al. Connecting the study of wild influenza with the potential for pandemic disease. Infection, Genetics and Evolution, 2013; 17:162-187.

\section{*Ganna Kovalenko}

E-mail: anna.kovalenko31@mail.ru 